\title{
Subjective memory complaints, vascular risk factors and psychological distress in the middle-aged: a cross-sectional study
}

\author{
Matt B Paradise ${ }^{*}$, Nick S Glozier ${ }^{1}$, Sharon L Naismith', Tracey A Davenport ${ }^{2}$ and lan B Hickie ${ }^{1}$
}

\begin{abstract}
Background: Subjective memory complaints (SMC) are common but their significance is still unclear. It has been suggested they are a precursor of mild cognitive impairment (MCl) or dementia and an early indicator of cognitive decline. Vascular risk factors have an important role in the development of dementia and possibly $\mathrm{MCl}$. We therefore aimed to test the hypothesis that vascular risk factors were associated with SMC, independent of psychological distress, in a middle-aged community-dwelling population.

Methods: A cross-sectional analysis of baseline data from the 45 and Up Study was performed. This is a cohort study of people living in New South Wales (Australia), and we explored the sample of 45, 532 participants aged between 45 and 64 years. SMC were defined as 'fair' or 'poor' on a self-reported five-point Likert scale of memory function. Vascular risk factors of obesity, diabetes, hypertension, hypercholesterolemia and smoking were identified by self-report. Psychological distress was measured by the Kessler Psychological Distress Scale. We tested the model generated from a randomly selected exploratory sample $(n=22,766)$ with a confirmatory sample of equal size.

Results: 5, 479/45, 532 (12\%) of respondents reported SMC. Using multivariate logistic regression, only two vascular risk factors: smoking (OR 1.18; $95 \% \mathrm{Cl}=1.03-1.35)$ and hypercholesterolaemia $(\mathrm{OR} 1.19 ; 95 \% \mathrm{Cl}=1.04-1.36)$ showed a small independent association with SMC. In contrast psychological distress was strongly associated with SMC. Those with the highest levels of psychological distress were $7.00(95 \% \mathrm{Cl}=5.41-9.07)$ times more likely to have SMC than the non-distressed. The confirmatory sample also demonstrated the strong association of SMC with psychological distress rather than vascular risk factors.

Conclusions: In a large sample of middle-aged people without any history of major affective illness or stroke, psychological distress was strongly, and vascular risk factors only weakly, associated with SMC, although we cannot discount psychological distress acting as a mediator in any association between vascular risk factors and SMC. Given this, clinicians should be vigilant regarding the presence of an affective illness when assessing middle-aged patients presenting with memory problems.
\end{abstract}

\section{Background}

Subjective memory complaints (SMC) are common and strongly associated with age. Estimates of their community prevalence have ranged from $11 \%$ [1] in 65 to 85 year olds to over $88 \%$ in those over the age of 85 years [2]. In Australia, Jorm et al. [3] found a prevalence of $10 \%$ in those with an average age of 62 years. There is

\footnotetext{
* Correspondence: matthew.paradise@sydney.edu.au

${ }^{1}$ Brain \& Mind Research Institute, The University of Sydney, Building F, 94

Mallet Street, Camperdown, NSW 2050, Australia

Full list of author information is available at the end of the article
}

uncertainty regarding the significance of SMC. They may be an early marker of cognitive decline with an underlying pathological basis, a feature of normal ageing and/or a reflection of psychological distress.

Cross-sectional studies have not consistently found an independent association between SMC and objective cognitive impairment [4]. In contrast, longitudinal studies have reported a strong association between SMC and the subsequent development of dementia or cognitive decline over periods of one to seven years [4-7]. Support for the pathological basis of SMC is further supported by recent
C Biomed Central 
neuroimaging studies, which have reported that euthymic individuals with memory complaints, free from significant objective deficits have early signs of Alzheimer's Disease (AD) pathology on MRI, such as medial-temporal lobe atrophy $[8,9]$.

Vascular risk factors such as diabetes, smoking, obesity, hypertension and hypercholesterolaemia are well established as risk factors in the development of dementia [10,11] and MCI [12-15]. The exact mechanism for this is unclear, but there is considerable interest in the vascular hypothesis of $\mathrm{AD}$, where vascular risk factors lead to cerebral hypoperfusion and later neurodegeneration [16]. To our knowledge only two studies, both cross-sectional, have examined the relationship between vascular risk factors and SMC, with conflicting results $[3,17]$. Neither of these studies examined the SMC-vascular risk factor association as their primary analysis.

There is also a strong association between SMC and depression [18-20], such that several studies have reported that after adjustment for mood, there is no longer an association of SMC with objective memory deficits [3,20,21]. There is also an association between vascular risk factors and depression [22,23] and indeed cerebrovascular disease in depression is predictive of poor prognosis and progression to dementia [24]. Any observed relationship between vascular risk factors and SMC may therefore be confounded/mediated by depression. Identification of the relative contribution of vascular risk factors and depression as potentially modifiable determinants of SMC in older people may enable early intervention strategies to prevent subsequent cognitive decline [25] and dementia, guiding both primary and secondary prevention approaches [25].

The objective of this study is to examine the associations between SMC, vascular risk factors and psychological distress. Our hypothesis is that vascular risk factors will be associated with SMC. Further, that this association will be independent of psychological distress.

\section{Methods}

We used data from the 45 and Up Study [26], a very large study of healthy ageing, in the state of New South Wales (NSW), Australia. As detailed elsewhere [26], participants were recruited through the Medicare Australia enrolment database, which provides almost complete coverage of the general population. Eligible individuals were mailed an invitation to take part, an information leaflet, the study questionnaire, a consent form and a reply paid envelope. The participation rate of the 45 and Up Study was approximately $18 \%$ for the first 100, 000 participants [26]. We gained permission from The Sax Institute to use data from the 45 and Up Study dataset and ethical approval had been granted from the relevant ethics committees.
We limited our cohort to those aged between 45 and 64 years to reflect the early intervention approach [25]. Additionally, by limiting the sample to this age-range we attempted to minimise the chances that the sample would include people with pre-existing dementia. For the initial analysis, we also excluded those who had reported having been diagnosed with a stroke or receiving psychiatric medication for depression or anxiety, because of the known cognitive sequelae of these conditions [27].

\section{The 45 and Up Study questionnaire}

All measures were extracted from the 45 and Up Study questionnaire [see 28]. This contained questions about demographic information, vascular risk factors and psychological distress.

Age was grouped into five-year intervals (i.e. 45-49 years, 50-54 years, 55-59 years, 60-64 years) and education was grouped into three levels (low, medium, high), according to both a priori assumptions and observations of their odds ratios. The three education levels were determined by whether the individual had left school early without a leaving certificate, had completed high school or had gone on to attain tertiary qualifications.

Five vascular risk factors were able to be considered; the presence of obesity, diabetes, whether the person was a current smoker and whether the individual was currently being treated for hypertension or hypercholesterolaemia. Obesity was defined as a Body Mass Index (BMI) greater than or equal to 30, according to World Health Organisation standards. The BMI was imputed using the weight and height recorded [29]. The presence of diabetes was determined by the question; "Has a doctor EVER told you that you have... diabetes?". The participant's smoking status was determined by the question "Are you are regular smoker now?" Treatment for hypertension and hypercholesterolaemia were determined by the questions "In the last month have you been treated for high blood pressure?" and "...high blood cholesterol?"

Psychological distress was assessed by the 10-item Kessler Psychological Distress Scale (K10) [30], which provides a global measure of distress based on depressive and anxiety symptoms experienced in the last four weeks. The cut-off scores were based on the 'Clinical Research Unit for Anxiety and Depression' levels [31] and have been validated by the Australian Bureau of Statistics [32,33]. Each item was scored from 1 for 'none of the time' to 5 for 'all of the time'. Scores for the ten items were then summed, yielding a minimum possible score of 10 and a maximum possible score of 50. Low scores of 10-15 indicate low levels of psychological distress, scores ranging from 16-29 'moderate' levels of psychological distress and high scores of 30-50 indicate 'severe' levels of psychological distress. 
The primary outcome variable of SMC was identified using a five-point Likert scale in which participants were asked "In general, how would you rate your memory?", with a choice of the following responses ' 1 - poor', '2 - fair', '3 - good', '4 - very good' or '5 - excellent'. Those rating their memory as 'fair' or 'poor' were defined as experiencing SMC. This approach and cut-off point is consistent with previous studies that have examined SMC $[34,35]$.

\section{Statistical analyses}

All data were analysed using the Statistical Package for the Social Sciences (SPSS 17.0 for Windows, Chicago, USA). Only those participants with full data were included in the statistical analyses.

We generated baseline characteristics of the 45, 532 participants. Two univariate analyses were run. Firstly, we examined the associations between demographic information, vascular risk factors and psychological distress with SMC. We then analysed the association between vascular risk factors and psychological distress. For dichotomous and categorical variables, odds-ratios of their association with SMC were produced. High education was used as the reference group based on the a priori assumption that lower education would be associated with SMC.

The SPSS Random Number Generator was used to create two separate datasets of equal size $(n=22,766)$ for exploratory and confirmatory model analyses. Chisquared tests were used to determine if there was any significant difference in demographic information, vascular risk factors or psychological distress between the exploratory and confirmatory samples.

All variables were then entered into exploratory logistic regression analyses, using the 'enter' method. There were four models generated. Model 1 considered demographic variables. Model 2 used demographic variables and the measure of psychological distress. Model 3 included demographic variables and vascular risk factors. The final model, Model 4, included demographic variables, vascular risk factors and a measure of psychological distress.

Finally, based on sound statistical results and a priori hypotheses, Model 4 was considered to be the most robust and was subsequently imposed on the confirmatory dataset to test its validity. For all analyses, we took the conservative approach of setting the significance level at $\mathrm{p}<0.001$, to reduce the chance of a Type-1 error given our large sample size.

\section{Results}

Of the 103, 041 total respondents, 55, 685 were aged less than 65 years and had not had a stroke or received treatment for depression and anxiety within the last month. Of these, 45, 533 participants had complete data available for all variables.

Demographic, vascular risk factor and psychological distress characteristics are shown in Table 1. SMC were strongly associated with low education and male gender, the presence of diabetes, being a current smoker and receiving treatment for hypercholesterolaemia. Obesity and receiving treatment of hypertension were not associated with SMC. Psychological distress had the strongest association with SMC. Those with the greatest psychological distress (i.e. K10 category of 'severe') had an odds ratio of 7.68 (95\% CI $=6.38-9.24)$ of having SMC compared to those with the least psychological distress.

Table 2 shows the association of vascular risk factors with psychological distress. Obesity, diabetes, being a current smoker and receiving treatment for hypercholesterolaemia were associated with psychological distress.

There were no significant differences in any of the baseline characteristics between the exploratory and confirmatory samples. Table 3 shows Models 1, 2, 3 and 4 of the multivariate analysis generated with the exploratory sample. Model 1 demonstrates that male gender and low education, but not age, were associated with SMC. These results were not attenuated by the presence of psychological distress in Model 2, which was strongly associated with SMC. Model 3 demonstrates that once adjusted for demographic variables, the only factor vascular risk factor that remained significantly associated with SMC in our conservative approach was being a current smoker (being treated for hypercholesterolaemia and diabetes both showed a trend towards association with SMC; $\mathrm{p}=0.002$ ). When adjusted for the presence of psychological distress in Model 4, the association between vascular risk factor and SMC further weakened, such that even in this very large sample, there were no statistically significant associations at the $\mathrm{p}<0.001$ level although both being a current smoker and hypercholesterolaemia treatment were associated at standard levels of significance. In all analyses, psychological distress had the strongest association with SMC. When fully adjusted, those with 'severe' psychological distress still had 7.00 times the odds (95\% CI $=5.41-9.07)$ of SMC.

The final Model 4 was imposed on into the confirmatory sample of 22, 766. This confirmed that male gender (OR 1.30; 95\% CI = 1.19 - 1.41) and low education (OR $1.68 ; 95 \% \mathrm{CI}=1.51-1.88$ ) were associated with SMC, but age was not. As seen in the exploratory dataset, in the presence of both demographic variables and psychological distress, no vascular risk factors were associated with SMC. Severe psychological distress was again strongly associated with SMC with a similar odds ratio of $6.86(95 \% \mathrm{CI}=5.20-9.05)$. 
Table 1 Characteristics of the 45 and Up Study sample and association of variables with SMC, N = 45, 532

\begin{tabular}{|c|c|c|c|c|}
\hline & Total & $\begin{array}{c}\text { SMC } \\
\text { (n, column \%) }\end{array}$ & $\begin{array}{c}\text { No SMC } \\
\text { (n, column \%) }\end{array}$ & Odds ratio $(95 \% \mathrm{Cl})$ \\
\hline $\mathbf{N}$ & 45,532 & 5,479 (12.0\%) & $40,053(88.0 \%)$ & \\
\hline \multicolumn{5}{|l|}{ Demographics } \\
\hline \multicolumn{5}{|l|}{ Age } \\
\hline-45 to 49 years & 9,582 & 1, $152(21.0 \%)$ & $8,430(21.0 \%)$ & 1.00 \\
\hline-50 to 54 years & 12,237 & 1, $441(26.3 \%)$ & $10,796(27.0 \%)$ & $0.98(0.90-1.06)$ \\
\hline-55 to 59 years & 12,712 & $1,510(27.6 \%)$ & $11,202(28.0 \%)$ & $0.99(0.91-1.07)$ \\
\hline-60 to 64 years & 11,001 & 1, $376(25.1 \%)$ & $9,625(24.0 \%)$ & $1.05(0.96-1.14)$ \\
\hline \multicolumn{5}{|l|}{ Gender } \\
\hline -Male & 20,606 & $2,674(48.8 \%)$ & 17, 932 (44.8\%) & $1.18(1.11-1.24)^{*}$ \\
\hline -Female & 24,926 & 2, $805(51.2 \%)$ & $22,121(55.2 \%)$ & \\
\hline \multicolumn{5}{|l|}{ Education } \\
\hline -High & 13,743 & 1, $071(19.5 \%)$ & $12,672(31.6 \%)$ & 1.00 \\
\hline -Medium & 19,856 & $2,462(44.9 \%)$ & 17, 394 (43.4\%) & $1.68(1.55-1.81)^{*}$ \\
\hline -Low & 11,933 & 1, $946(35.5 \%)$ & 9, 987 (24.9\%) & $2.31(2.13-2.50)^{*}$ \\
\hline \multicolumn{5}{|l|}{ Vascular risk factors } \\
\hline Obesity & 10,147 & 1, $306(23.8 \%)$ & $8,841(22.1 \%)$ & $1.11(1.03-1.18)$ \\
\hline -non-obesity & 35,385 & 4, $173(76.2 \%)$ & $31,212(77.9 \%)$ & \\
\hline Diabetes & 2,475 & 379 (6.9\%) & 2, 096 (5.2\%) & $1.35(1.20-1.51)^{*}$ \\
\hline -no diabetes & 43, 057 & 5, $100(93.1 \%)$ & 37, 957 (94.8\%) & \\
\hline Current smoker & 3,928 & $607(11.1 \%)$ & $3,321(8.3 \%)$ & $1.38(1.26-1.51)^{*}$ \\
\hline -non-smoker & 41,604 & 4, $872(88.9 \%)$ & $36,732(91.7 \%)$ & \\
\hline Treatment for hypertension & 7,338 & $928(16.9 \%)$ & $6,410(16.0 \%)$ & $1.07(0.99-1.15)$ \\
\hline -no treatment for hypertension & 38,194 & 4, $551(83.1 \%)$ & $33,643(84.0 \%)$ & \\
\hline Treatment for hypercholesterolaemia & 4,892 & $692(12.6 \%)$ & 4, $200(10.5 \%)$ & $1.23(1.13-1.35)^{*}$ \\
\hline -no treatment for hypercholesterolaemia & 40,640 & 4, $787(87.4 \%)$ & $35,853(89.5 \%)$ & \\
\hline \multicolumn{5}{|l|}{ Psychological distress } \\
\hline K10-low level of distress & 35,713 & 3, $139(57.3 \%)$ & $32,574(81.3 \%)$ & 1.00 \\
\hline - moderate level of distress & 9,344 & $2,138(39.0 \%)$ & 7, $206(18.0 \%)$ & $3.08(2.90-3.27)^{*}$ \\
\hline - severe level of distress & 475 & $202(3.7 \%)$ & $273(0.7 \%)$ & $7.68(6.38-9.24)^{*}$ \\
\hline
\end{tabular}

Note: ${ }^{*} p<0.001$.

Table 2 Association of vascular risk factors with psychological distress, $N=45,532$

\begin{tabular}{|c|c|c|c|c|c|}
\hline \multirow{3}{*}{ Vascular risk factors } & \multicolumn{5}{|c|}{ Level of psychological distress - K10 } \\
\hline & \multirow[t]{2}{*}{$\mathbf{N}$} & \multicolumn{3}{|c|}{ n (\%) } & \multirow[t]{2}{*}{ Chi-square } \\
\hline & & Low & Moderate & Severe & \\
\hline Obesity & 10,147 & $7,629(75.2 \%)$ & $2,363(23.3 \%)$ & $155(1.5 \%)$ & $95.61^{*}$ \\
\hline -non-obesity & 35,385 & $28,084(79.4 \%)$ & $6,981(19.7 \%)$ & $320(0.9 \%)$ & \\
\hline Diabetes & 2,475 & 1, $821(73.6 \%)$ & $599(24.2 \%)$ & $55(2.2 \%)$ & $60.03^{*}$ \\
\hline -no diabetes & 43,057 & $33,892(78.7 \%)$ & $8,745(20.3 \%)$ & $420(1.0 \%)$ & \\
\hline Current smoker & 3,928 & 2, $752(70.1 \%)$ & 1, $065(27.1 \%)$ & $111(2.8 \%)$ & $260.39^{*}$ \\
\hline -non-smoker & 41,604 & 32, $961(79.2 \%)$ & 8, $279(19.9 \%)$ & $364(0.9 \%)$ & \\
\hline Treatment for hypertension & 7,338 & $5,653(77.0 \%)$ & $1,607(21.9 \%)$ & $78(1.1 \%)$ & 10.30 \\
\hline -no treatment for hypertension & 38,194 & $30,060(78.7 \%)$ & 7, $737(20.3 \%)$ & $397(1.0 \%)$ & \\
\hline Treatment for hypercholesterolaemia & 4,892 & 3, $731(76.3 \%)$ & 1, $098(22.4 \%)$ & 63 (1.3\%) & $16.30^{*}$ \\
\hline -no treatment for hypercholesterolaemia & 40,640 & $31,892(78.7 \%)$ & $8,246(20.3 \%)$ & $412(1.0 \%)$ & \\
\hline
\end{tabular}

Note: ${ }^{*} p<0.001$. 
Table 3 Multivariate models of associations of SMC using the exploratory sample, $\mathbf{N}=22,766$

\begin{tabular}{|c|c|c|c|c|}
\hline & $\begin{array}{c}\text { Model } 1 \\
\text { Odds ratio }(95 \% \mathrm{Cl})\end{array}$ & $\begin{array}{c}\text { Model } 2 \\
\text { Odds ratio }(95 \% \mathrm{Cl})\end{array}$ & $\begin{array}{c}\text { Model } 3 \\
\text { Odds ratio }(95 \% \mathrm{Cl})\end{array}$ & $\begin{array}{c}\text { Model } 4 \\
\text { Odds ratio }(95 \% \mathrm{Cl})\end{array}$ \\
\hline \multicolumn{5}{|l|}{ Demographics } \\
\hline \multicolumn{5}{|l|}{ Age } \\
\hline-45 to 49 years & 1.00 & 1.00 & 1.00 & 1.00 \\
\hline-50 to 54 years & $0.97(0.86-1.09)$ & $1.01(0.90-1.14)$ & $0.97(0.86-1.09)$ & $1.01(0.90-1.15)$ \\
\hline-55 to 59 years & $0.96(0.85-1.08)$ & $1.09(0.96-1.22)$ & $0.96(0.85-1.08)$ & $1.08(0.96-1.22)$ \\
\hline-60 to 64 years & $0.95(0.85-1.08)$ & $1.09(0.99-1.23)$ & $0.95(0.84-1.07)$ & $1.08(0.95-1.22)$ \\
\hline \multicolumn{5}{|l|}{ Gender } \\
\hline -Male & $1.26(1.16-1.36)^{*}$ & $1.29(1.18-1.40)^{*}$ & $1.23(1.13-1.34)^{*}$ & $1.27(1.17-1.40)^{*}$ \\
\hline \multicolumn{5}{|l|}{ Education } \\
\hline -High & 1.00 & 1.00 & 1.00 & 1.00 \\
\hline -Medium & $1.62(1.46-1.80)^{*}$ & $1.59(1.43-1.77)^{*}$ & $1.59(1.43-1.77)^{*}$ & $1.58(1.42-1.76)^{*}$ \\
\hline -Low & $2.22(1.98-2.48)^{*}$ & $2.06(1.84-2.31)^{*}$ & $2.14(1.91-2.40)^{*}$ & $2.03(1.81-2.28)^{*}$ \\
\hline \multicolumn{5}{|l|}{ Vascular risk factors } \\
\hline Obesity & & & $0.98(0.89-1.08)$ & $0.94(0.85-1.03)$ \\
\hline Diabetes & & & $1.21(1.03-1.43)$ & $1.13(0.96-1.34)$ \\
\hline Current smoker & & & $1.31(1.15-1.49)^{*}$ & $1.18(1.03-1.35)$ \\
\hline Treatment for hypertension & & & $0.97(0.86-1.09)$ & $0.96(0.85-1.08)$ \\
\hline Treatment for hypercholesterolaemia & & & $1.22(1.07-1.39)$ & $1.19(1.04-1.36)$ \\
\hline \multicolumn{5}{|l|}{ Psychological distress } \\
\hline K10-low level of distress & & 1.00 & & 1.00 \\
\hline - moderate level of distress & & $2.96(2.71-3.23)^{*}$ & & $2.94(2.69-3.21)^{*}$ \\
\hline - severe level of distress & & $7.21(5.57-9.32)^{*}$ & & $7.00(5.41-9.07)^{*}$ \\
\hline
\end{tabular}

Notes: ${ }^{*} p$ < 0.001; Model 1 - demographic variables; Model 2 - demographic variables and psychological distress; Model 3 - demographic variables and vascular risk factors; Model 4 - demographic variables, vascular risk factors and psychological distress.

\section{Discussion}

In an Australian community sample of 45 to 64 year olds, who are not currently receiving treatment for depression or anxiety and who are unlikely to have significant cognitive impairment, SMC are common, with a prevalence of $12 \%$. In univariate analysis, the vascular risk factors of diabetes, being a current smoker and treatment for hypercholesterolaemia were associated with SMC. In multivariate analyses, when adjusted for psychological distress and demographics, vascular risk factors showed only weak associations with SMC.. This may be because of the confounding effect of gender and education, with post-hoc analyses showing male gender and less education were strongly associated with the presence of vascular risk factors.

The lack of strong association of vascular risk factors with SMC is consistent with Jorm et al. [3], who reported that diabetes, 'heart troubles' and a history of strokes were not associated with memory complaints in multivariate analysis, in an Australian sample of communitydwelling 60 to 64 years old with generally good cognition. This is also consistent with Stewart et al. [17] who found that in an Afro-Caribbean population hypertension, diabetes, electrocardiography-defined ischemia, cholesterol or triglyceride levels were not associated with memory complaints (although having had a stroke was a significant risk).

In contrast to vascular risk factors, there was a strong independent association between psychological distress and SMC. This is consistent with other literature [18-20] and may reflect the common depressive symptoms of poor memory and concentration. There may also be a tendency in subjects with significant psychological distress to have a negative attribution bias and therefore over-report memory complaints [36]. Memory complaints in those with high levels of psychological distress may also represent a common underlying pathophysiology. Depression, for example is now recognised as an independent modifiable risk-factor for cognitive decline [37] and conversion of MCI to dementia [38]. Several mechanisms have been postulated for this relationship including the neurotoxic effects of chronic hypercortisolaemia, reduced levels of neurotrophic factors [39], alterations in glial-neuronal networks, vascular disease and inflammatory processes [40]. Indeed, older patients with depression have reduced hippocampal size, which in turn, is associated with poorer memory [40].

Our data shows a strong association between vascular risk and psychological distress. This is consistent with the literature, where the association between vascular 
risk factors and depression is well documented [23]. We hypothesised that psychological distress might mediate any relationship between vascular risk factors and SMC. However, the general lack of associations between vascular risk factors and SMC seen in Model 3 would suggest that any such mediation is minimal. Further exploration of these complex relationships is warranted in longitudinal studies.

There are several strengths of this study. It is the largest study to date that examines the relationship between psychological distress, vascular risk factors and SMC. The questions were all taken from validated questionnaires used extensively in Australian populations. Our finding of a SMC prevalence of $12 \%$ is consistent with the community samples from the literature $[1,3]$.

The major limitation of this study is the uncertainty regarding the direction of causality of any observed association: for example, it may be that SMC lead to psychological distress, rather than the other way around. We also cannot correlate the measure of SMC with an objective cognitive assessment. We could not specifically exclude cases of dementia or $\mathrm{MCI}$ although by limiting the cohort to those aged less than 65 , we are unlikely to have many cases. A recent meta-analysis found a dementia prevalence rate of $0.6 \%$ for those aged between 60 and 64 years in Australasia [41]. Also, the ability to complete, sign and return the questionnaire would exclude those with significant cognitive decline. In any event, as seen with stroke, these cases may be unlikely to dramatically affect the results.

The presence of hypertension and hypercholesterolaemia were determined by the prescription of medication for these conditions. There may therefore be undetected individuals with these vascular risk factors and those receiving treatments for these conditions may paradoxically be at a reduced risk.

Finally, there is the effect of the size of the study. Analyses of such large samples may result in Type I errors. Such studies always result in a trade-off between efficiency and the diminution of measurement errors in a large sample against the ability of such measures to provide valid evaluations at an individual level. Although we do not anticipate any significant bias in the response, the error will serve to reduce the observed estimate of the association. The similar results found in the exploratory and confirmatory datasets strengthen the validity of our conclusions.

All our measures are self-report and as such, our exposure may be subject to information bias, with those people reporting SMC potentially being less likely to recall the presence of vascular risk factors. This would lead us to have underestimated any real association between vascular risk factors and SMC.

The participation rate of the 45 and Up Study was low, at $18 \%$ for the first 100, 000 participants. Although this raises questions about the representativeness of the sample, comparison with the NSW Population Health Survey demonstrated good generalisability [42].

\section{Conclusions}

$\mathrm{SMC}$ are common in community-dwelling middle-aged adults without any history of major affective illness or stroke. Vascular risk factors were not independently associated with SMC. Psychological distress was highly associated with SMC as well as with vascular risk factors.

This finding adds some support to the concept of vascular depression [43] and emphasises the need for clinicians to take SMC seriously in their patients, as a common indicator of undetected psychological distress and possible affective illness. This may best be achieved through primary care education programmes highlighting early detection and management of psychological distress in at-risk groups $[44,45]$.

The complex relationship between memory complaints, vascular risk and psychological distress needs further exploration in longitudinal studies. A greater understanding of SMC may allow early intervention to prevent psychological distress and potentially modify cognitive decline.

\section{Acknowledgements}

The 45 and Up Study is managed by The Sax Institute in collaboration with major partner Cancer Council New South Wales; and partners the National Heart Foundation of Australia (NSW Division); NSW Health; beyondblue: the national depression initiative; Ageing, Disability and Home Care, Department of Human Services NSW; and UnitingCare Ageing.

Dr Paradise, A/Prof Naismith and Prof Hickie and are funded by an NHMRC Australia Fellowship awarded to Prof Hickie.

\section{Author details}

'Brain \& Mind Research Institute, The University of Sydney, Building F, 94 Mallet Street, Camperdown, NSW 2050, Australia. ${ }^{2}$ Academic Research \& Statistical Consulting, 5 Herbert Street, West Ryde, NSW 2114, Australia.

\section{Authors' contributions}

MBP conceived the study and wrote the first draft. NSG helped with the study design, statistics and editing the manuscript. SLN provided input into the study design and helped draft the manuscript. TAD provided statistical advice and helped edit the manuscript. IBH provided overall supervision for the project and helped draft the manuscript. All authors read and approved the final manuscript.

\section{Competing interests}

The authors declare that they have no competing interests.

Received: 16 February 2011 Accepted: 1 July 2011

Published: 1 July 2011

\section{References}

1. Geerlings Ml, Jonker C, Bouter LM, Ader HJ, Schmand B: Association between memory complaints and incident Alzheimer's disease in elderly people with normal baseline cognition. Am J Geriatr Psychiatry 1999, 156(4):531-537.

2. Larrabee GJ, Crook TH: Estimated prevalence of age-associated memory impairment derived from standardized tests of memory function. Int Psychogeriatr 1994, 6(1):95-104.

3. Jorm AF, Butterworth P, Anstey K, Christensen H, Easteal S, Maller J, Mather KA, Turakulov RI, Wen W, Sachdev P: Memory complaints in a 
community sample aged 60-64 years: associations with cognitive functioning, psychiatric symptoms, medical conditions, APOE genotype, hippocampus and amygdala volumes, and white-matter hyperintensities. Psychol Med 2004, 34(8):1495-1506.

4. Reid LM, Maclullich AMJ: Subjective memory complaints and cognitive impairment in older people. Dement Geriatr Cogn Disord 2006, 22(5-6):471-485. 5. Jessen F, Wiese B, Bachmann C, Eifflaender-Gorfer S, Haller F, Kolsch H, Luck T, Mosch E, van den Bussche H, Wagner M, Wollny A, Zimmermann T, Pentzek M, Riedel-Heller SG, Romberg H-P, Weyerer S, Kaduszkiewicz H, Maier W, Bickel H: Prediction of dementia by subjective memory impairment: effects of severity and temporal association with cognitive impairment. Arch Gen Psychiatry 67(4):414-422.

6. Jonker C, Geerlings Ml, Schmand B: Are memory complaints predictive for dementia? A review of clinical and population-based studies. Int J Geriatr Psychiatry 2000, 15(11):983-991

7. Reisberg B, Prichep L, Mosconi L, John ER, Glodzik-Sobanska L, Boksay I, Monteiro I, Torossian C, Vedvyas A, Ashraf N, Jamil IA, de Leon MJ: The premild cognitive impairment, subjective cognitive impairment stage of Alzheimer's disease. Alzheimers Dement 2008, 4(1 Suppl 1):S98-S108.

8. Saykin AJ, Wishart HA, Rabin LA, Santulli RB, Flashman LA, West JD, McHugh TL, Mamourian AC: Older adults with cognitive complaints show brain atrophy similar to that of amnestic MCl. Neurology 2006, 67(5):834-842.

9. Chao LL, Mueller SG, Buckley ST, Peek K, Raptentsetseng S, Elman J, Yaffe K, Miller BL, Kramer JH, Madison C, Mungas D, Schuff N, Weiner MW: Evidence of neurodegeneration in brains of older adults who do not yet fulfill $\mathrm{MCl}$ criteria. Neurobiol Aging 2008, 31(3):368-377.

10. Luchsinger JA, Reitz C, Honig LS, Tang MX, Shea S, Mayeux R: Aggregation of vascular risk factors and risk of incident Alzheimer disease. Neurology 2005, 65(4):545-551.

11. Gorelick PB: Risk factors for vascular dementia and Alzheimer disease. Stroke 2004, 35(11 Suppl 1):2620-2622.

12. Kivipelto M, Helkala EL, Hanninen T, Laakso MP, Hallikainen M, Alhainen $K$, Soininen $H$, Tuomilehto J, Nissinen A: Midlife vascular risk factors and late-life mild cognitive impairment: A population-based study. Neurology 2001, 56(12):1683-1689.

13. Solfrizzi V, Panza F, Colacicco AM, D'Introno A, Capurso C, Torres F Grigoletto F, Maggi S, Del Parigi A, Reiman EM, Caselli RJ, Scafato E, Farchi G, Capurso A: Vascular risk factors, incidence of $\mathrm{MCl}$, and rates of progression to dementia. Neurology 2004, 63(10):1882-1891.

14. Ravaglia G, Forti P, Maioli F, Martelli M, Servadei L, Brunetti N, Pantieri G, Mariani E: Conversion of mild cognitive impairment to dementia: predictive role of mild cognitive impairment subtypes and vascular risk factors. Dement Geriatr Cogn Disord 2006, 21(1):51-58.

15. Mariani E, Monastero R, Ercolani S, Mangialasche F, Caputo M, Feliziani FT, Vitale DF, Senin U, Mecocci P, Re GSG: Vascular risk factors in mild cognitive impairment subtypes. Findings from the ReGAl project. Dement Geriatr Cogn Disord 2007, 24(6):448-456.

16. de la Torre JC: Is Alzheimer's disease a neurodegenerative or a vascular disorder? Data, dogma, and dialectics. Lancet Neurol 2004, 3(3):184-190.

17. Stewart R, Russ C, Richards M, Brayne C, Lovestone S, Mann A: Depression, APOE genotype and subjective memory impairment: a cross-sectional study in an African-Caribbean population. Psychol Med 2001, 31(3):431-440.

18. Tobiansky R, Blizard R, Livingston G, Mann A: The Gospel Oak Study stage IV: the clinical relevance of subjective memory impairment in older people. Psychol Med 1995, 25(4):779-786.

19. Hanninen T, Reinikainen KJ, Helkala EL, Koivisto K, Mykkanen L, Laakso M, Pyorala K, Riekkinen PJ: Subjective memory complaints and personality traits in normal elderly subjects. J Am Geriatr Soc 1994, 42(1):1-4.

20. Minett TSC, Dean JL, Firbank M, English P, O'Brien JT: Subjective memory complaints, white-matter lesions, depressive symptoms, and cognition in elderly patients. Am J Geriatr Psychiatry 2005, 13(8):665-671.

21. Minett TSC, Da Silva RV, Ortiz KZ, Bertolucci PHF: Subjective memory complaints in an elderly sample: a cross-sectional study. Int J Geriatr Psychiatry 2008, 23(1):49-54.

22. Hickie I, Scott E, Mitchell P, Wilhelm K, Austin MP, Bennett B: Subcortical hyperintensities on magnetic resonance imaging: clinical correlates and prognostic significance in patients with severe depression. Biol Psychiatry 1995, 37(3):151-160.

23. Hickie I, Scott E: Late-onset depressive disorders: a preventable variant of cerebrovascular disease? Psychol Med 1998, 28(5):1007-1013.
24. Hickie I, Scott E, Wilhelm K, Brodaty H: Subcortical hyperintensities on magnetic resonance imaging in patients with severe depression-a longitudinal evaluation. Biol Psychiatry 1997, 42(5):367-374

25. Naismith SL, Glozier NS, Burke D, Carter PE, Scott E, Hickie IB: Early intervention for cognitive decline: is there a role for multiple medical or behavioural interventions? Early Interv Psychiatry 2009, 3:19-27.

26. Banks E, Redman S, Jorm L, Armstrong B, Bauman A, Beard J, Beral V, Byles J, Corbett S, Cumming R, Harris M, Sitas F, Smith W, Taylor L, Wutzke S, Lujic S: Cohort profile: the 45 and up study. Int J Epidemiol 2008, 37(5):941-947.

27. Naismith SL, Hickie IB, Turner K, Little CL, Winter V, Ward PB, Wilhelm K, Mitchell P, Parker G: Neuropsychological performance in patients with depression is associated with clinical, etiological and genetic risk factors. J Clin Exp Neuropsychol 2003, 25(6):866-877.

28. The 45 and Up Study. [http://www.45andup.org.au].

29. WHO: Technical report series 894: Obesity: Preventing and managing the global epidemic. Geneva: World Health Organisation; 2000.

30. Kessler RC, Andrews G, Colpe LJ, Hiripi E, Mroczek DK, Normand SLT, Walters EE, Zaslavsky AM: Short screening scales to monitor population prevalences and trends in non-specific psychological distress. Psychol Med 2002, 32(6):959-976.

31. Clinical Research Unit for Anxiety and Depression (CRUfAD). [http://www. crufad.org].

32. 4817.0.55.001 - Information Paper: Use of the Kessler Psychological Distress Scale in ABS Health Surveys, Australia, 2001. [http://www.abs. gov.au/ausstats/abs@.nsf/mf/4817.0.55.001\#3.\%20Scoring\%20the\%20K10].

33. Andrews $G$, Slade T: Interpreting scores on the Kessler Psychological Distress Scale (K10). Aust N Z J Public Health 2001, 25(6):494-497.

34. Purser $J$, Fillenbaum GG, Wallace RB: Memory complaint is not necessary for diagnosis of mild cognitive impairment and does not predict 10-year trajectories of functional disability, word recall, or short portable mental status questionnaire limitations. J Am Geriatr Soc 2006, 54(2):335-338.

35. Ganguli M, Dodge HH, Shen C, DeKosky ST: Mild cognitive impairment, amnestic type: an epidemiologic study. Neurology 2004, 63(1):115-121.

36. Naismith SL, Longley WA, Scott EM, Hickie IB: Disability in major depression related to self-rated and objectively-measured cognitive deficits: a preliminary study. BMC Psychiatry 2007, 7:32.

37. Ownby RL, Crocco E, Acevedo A, John V, Loewenstein D: Depression and risk for Alzheimer disease - Systematic review, meta-analysis, and metaregression analysis. Arch Gen Psychiatry 2006, 63(5):530-538

38. Modrego PJ, Ferrandez J: Depression in patients with mild cognitive impairment increases the risk of developing dementia of Alzheimer type: a prospective cohort study. Arch Neurol 2004, 61(8):1290-1293.

39. Duman RS, Monteggia LM: A neurotrophic model for stress-related mood disorders. Biol Psychiatry 2006, 59(12):1116-1127.

40. Hickie I, Naismith S, Ward PB, Turner K, Scott E, Mitchell P, Wilhelm K, Parker G: Reduced hippocampal volumes and memory loss in patients with early- and late-onset depression. Br J Psychiatry 2005, 186:197-202.

41. Ferri CP, Prince M, Brayne C, Brodaty H, Fratiglioni L, Ganguli M, Hall K, Hasegawa K, Hendrie H, Huang YQ, Jorm A, Mathers C, Menezes PR, Rimmer E, Scazufca M: Global prevalence of dementia: a Delphi consensus study. Lancet 2005, 366(9503):2112-2117

42. Mealing NM, Banks E, Jorm LR, Steel DG, Clements MS, Rogers KD: Investigation of relative risk estimates from studies of the same population with contrasting response rates and designs. BMC Med Res Methodol 10:26.

43. Alexopoulos GS, Meyers BS, Young RC, Campbell S, Silbersweig D, Charlson M: 'Vascular depression' hypothesis. Arch Gen Psychiatry 1997, 54(10):915-922.

44. Hickie IB, Davenport TA, Scott EM, Hadzi-Pavlovic D, Naismith SL, Koschera A: Unmet need for recognition of common mental disorders in Australian general practice. Med J Aust 2001, 175(24):16

45. Naismith SL, Hickie IB, Scott EM, Davenport TA: Effects of mental health training and clinical audit on general practitioners' management of common mental disorders. Med J Aust 2001, 175(7):16.

\section{Pre-publication history}

The pre-publication history for this paper can be accessed here: http://www.biomedcentral.com/1471-244X/11/108/prepub

\section{doi:10.1186/1471-244X-11-108}

Cite this article as: Paradise et al:: Subjective memory complaints, vascular risk factors and psychological distress in the middle-aged: a crosssectional study. BMC Psychiatry 2011 11:108. 